\title{
Prediction of the yield of grains through artificial intelligence
}

\author{
Autores \\ Jose Silva, Noel Varela, Danelys Cabrera, Omar Lezama
}

\begin{abstract}
Grass turns out to be an appropriate food for cattle, mainly in tropical climate countries such as Latin American countries. This is due to the high number of species that can be used, the possibility of growing them year-round, the ability of the ruminant to use fibrous supplies and be an economic source (Sánchez et al., Data mining and big data. DMBD 2018. Lecture notes in computer science, vol 10943. Springer, Cham, 2018, [1]]). In this work, an application of neural networks was carried out in the forecasting of more accurate values of production and quality of grasslands.
\end{abstract}

Palabras clave:

Artificial intelligence, Forage, Grass, Neural networks 